\title{
Implementasi Maqashid Syariah dalam Sidang Itsbat Hilal Penentuan Awal Ramadhan
}

\author{
Ismail \\ IAIN Lhokseumawe \\ Email: ismail@iainlhokseumawe.ac.id \\ Abdul Ghofur \\ UIN Walisongo Semarang \\ Email:aghofur2009@gmail.com
}

\begin{abstract}
The trial of the initial determination of Ramadhan, Shawwal and Zulhijjah is often a criticism for those who say the initial determination of Ramadhan is in line with the reckoning system, it does not need a congregation hearing that consumes state money, leave it to the community to join the organization it believes. This paper explains the position of the congregation of itsbat to determine the beginning of Ramadan in the perspective of maqashid sharia. By analyzing the practice of the congregation trial and the prevailing rules in Indonesia, it can be concluded that the practice of the trial of the congregation has been classified as perfect for the initial determination of the month of Ramadan. In maqashid syariah, the trial of the initial determination of Ramadhan is included in the category of dharuriyyat in particular and hajiyat in general. The congregation is needed by the Muslim community of Indonesia, considering that to increase the value of benefit and reject the harm which is the core of maqashid sharia is in the trial of itsbat. Therefore, adhering to the congregation of itsbat is to maintain benefit while rejecting harm.
\end{abstract}

Keywords: maqashidsyariah, session of hilal itsbat, early ramadhan.

\begin{abstract}
Abstrak
Sidang itsbat penetuan awal Ramadhan, Syawal dan Zulhijjah sering menjadi kritikan bagi kalangan yang mengatakan penentuan awal Ramadhan memada dengan sistem hisab, tidak perlu sidang itsbat yang menghabiskan uang negara, serahkan saja pada masyarakat untuk ikut organisasi yang diyakini. Tulisan ini menjelaskan posisi sidang itsbat penentuan awal Ramadhan dalam perspektif maqashid syariah. Dengan menganalisa praktik sidang itsbat dan aturan yang berlaku di Indonesia, dapat disimpulkan bahwa praktik sidang itsbat sudah tergolong sempurna untuk penetapan awal bulan Ramadhan. Dalam maqashid syariah, sidang itsbat penetuan awal
\end{abstract}


Ramadhan termasuk dalam katagori dharuriyyat secara khusus dan hajiyat secara umum. Sidang itsbat sangat dibutuhkan oleh masyarakat muslim Indonesia, mengingat untuk meningkatkan nilai kemaslahatan dan menolak kemudharatan yang merupakan inti dari maqashid syariah ada dalam sidang itsbat. Oleh karenanya, mematuhi sidang itsbat adalah memelihara kemaslahatan sekaligus menolak kemudharan.

Kata Kunci: Maqashid Syariah, Sidang Itsbat Hilal dan Awal Ramadhan.

\section{Pendahuluan}

Di Indonesia, sidang itsbat penentuan awal bulan Ramadhan, Shawal dan Zulhijjah selalu menjadi titik perhatian masyarakat, selain menunggu untuk mengetahui sebuah ketetapan untuk memulai berpuasa, berhari raya Idul Fitri dan Idul Adha, juga untuk mengetahui potensi perbedaan dalam masyarakat Indonesia terhadap aktifitas ibadah puasa dan berhari raya tersebut. Perbedaan dalam mengawali puasa dan berhari raya sudah menjadi tontonan di Indonesia, hal ini disebabkan belum sepenuhnya pemerintah dijadikan otoritas tunggal dalam penetapan awal Ramadhan dan berhari raya oleh masyarakat Indonesia. Kegagalan ini menjadi peluang bagi ormas Islam di Indonesia dalam mengembangkan konsep simbolik untuk memperkuat identitas politik organisasi masing-masing.

Sidang itsbat selalu dilakukan pada tanggal 29 Syakban, Ramadhan dan Zulkaidah oleh pemerintah RI yang diwakili oleh Kementerian Agama dan diikut sertakan ormas-ormas Islam dan tokoh falak dan astronomi. Sidang itsbat di Indonesia adalah sebuah upaya pemerintah dalam mengakamodir keragaman beragama di Indonesia, mengingat konsep moderasi beragama harus dikedepankan oleh segenap lapisan masyarakat Indonesia. Hal ini dapat dilihat dari sasaran dan penetapan pemerintah dalam kebijakan pemerintah RI dalam menetapkan awal bulan qamariyah di Indonesia. Sasaran yang diharapkan dari sidang itsbat adalah meningkatnya kualitas pelayanan kehidupan beragama bagi seluruh lapisan masyarakat. Menyamakan persepsi penentuan awal bulan qamariyah. Dan meningkatnya kerukunan internal dan antar umat beragama dalam rangka terwujutnya kehidupan yang harmonis, toleransi dan saling menghormati. Sedangkan penetapan dari pemerintah diperlukan untuk mendapatkan keabsahan, mencegah kerancuan dan keraguan sistem pelaporan rukyah hilal, dan untuk mengedepankan penyatuan umat dengan menghilangkan perbedaan pendapat (Kementerian Agama 2019). 
Sidang itsbat penetapan awal bulan Ramadhan, Syawal dan Zulhijjah merupakan pekerjaan pemerintah, tentunya nilai kemaslahatan atau nilai maqashid syariah harus diutamakan, hal ini sesuai dengan kaidah fikih Tasharruf al imam 'ala raiyatih manuthun bi al mashlahah. Yang membahas tentang sidang itsbat hilal sangat banyak, Nihayatur Rohmah (2018), Otoritas dalam penetapan awal bulan qamariyah (konfrontasi antara pemimpin negara dan pemimpin ormas keagamaan), tulisan ini menjelaskan bahwa pemerintah yang paling cocok dijadikan otoritas tunggal dalam penetapan awl bulan qamariyah. Nihayatur Rohmah (2018), Dialog teori konflik dialektika-fungsional (meneropong dinamika sidang itsbat di Indonesia), tulisan ini menjelaskan bahwa perbedaan dalam penetapan awal bulan qamariyah denga hasil sidang itsbat ada nilai positif dan negatif. Positifnya, dengan adanya perbedaan hasil penetapan awal ramadhan dengan sidang itsbat akan memotifasi masyarakat untuk belajar tentang masalah rukyah hilal dan yang berkaitan dengan penentuan awal bulan Ramadhan. Sisi negatif adalah tibul keresahan masyarakat awam yang berakibat perpecahan atau retaknya ukhwah islamiah. Siti Tatmainul Qulub (2015), Telaah kritis putusan sidang itsbat penetapan awal bulan qamariyah di Indonesia dalam perspektif ushul fikih, tulisan ini menjelaskan kedudukan sidang itsbat hilal di Indonesia sangat dibutuhkan dan harus dilakukan oleh pemerintah sebagai landasan hukum berpuasa dan sebagai ikhtiar pemersatu umat dalam menerapkan maqashid syariah. Ahmad Wahidi (2011), Menyatukan penetapan 1 Ramadhan, Syawal dan Zulhijjah di Indonesia, tulisan ini menjelaskan ada dua pendekatan yang harus dilakukan dalam upaya penyatuan dalam penetapan awal bulan qamariyah, pertama pendekatan metodologis dan kedua pendekatan kekuasaan.

Dari hasil penelitian sebelunya, terlihat tulisan ini masih relevan dengan konteks dan masik layak untuk dibahas, karena tulisan ini mencoba menguraikan implementasi maqashid syariah dalam sidang itsbat penetapan awal Ramadhan di Indonesia. Untuk tetap fokus pembahasan sesuai dengan masalah, penulis merumuskan masalah yang akan dibahas dalam bentuk pertanyan. Bagaimana praktik sidang itsbat hilal di Indonesia? Termasuk dalam kategori mana sidang itsbat dalam konsep maqashid syariah? Dan sejauh mana nilai maqashid syariah dalam sidang itsbat hilal? Dalam menjawab semua pertanyaan, penulis menggunakan data pustaka atau dokumentasi kemudian dianalisis secara diskriftif dengan menggunakan pendekatan ushul fikih dan ilmu falak. 


\section{Maqashid Syariah}

Maqashid syariah merupakan sebuah konsep dalam melahirkan hukum dengan landasan nilai-nilai kemaslahatan umum. Sebelum terbentuk sebagai sebuah konsep yang mapan dalam sebuah disiplin ilmu yang mandiri dan sistematis, maqashid syariah telah melalui proses yang panjang mulai semenjak syariat lahir, yaitu semenjak masa Rasulullah masih hidup sampai era sekarang. Di masa Rasulullah, nilai-nilai maqashid syariah telah terlihat dalam setiap hukum yang diputuskan oleh Rasulullah, hal serupa juga terlihat pada masa sahabat. Pada masa tabi' in dan imam mazhab terlihat maqashid syariah tersimpan dalam metode ijtihad yang mereka gunakan, seperti istihsan, istislah, qiyas, dan sadd al-dhari'ah (Safriadi 2014).

Setelah masa imam mazhab, maqashid syariah sebagai metode penetapan hukum kian sempurna. Ada beberapa tokoh penting yang perlu diperhatikan yang tergolong sebagai yang berjasa dalam melahirkan konsep maqashid syariah dalam studi hukum Islam, pertama masa Al-Juwaini $(\mathrm{W} .479 \mathrm{H})$ yang telah membagikan maqashid syariah kepada dharuriyah, hajiyah dan tahsiniyah. Kemudian teori maqashid syariah diteruskan oleh imam Al-Ghazali (W.505 H) dengan memunculkan 5 maksud syara' dalam penetapan hukum, yaitu menjaga agama, jiwa, akal, keturunan dan menjaga harta. Selanjutnya dikembangkan oleh al-Razi (W.606 H). Kemudian 'Izzuddin bin Abdussalam (W. 660 H). Selanjutnya dikembangkan oleh muridnya 'Izzuddin yaitu al-Qarafi (W. 648 H). Kemudian dikembangkan oleh Ibnu Taimiyah (W.728 H). Setelah nya hadir al-Tufi (W. 716 H). Seterusnya hadir al-Syatibi (W. H). Dan terahir adalah Ibnu Asyur (W.1393 $\mathrm{H})$. Inilah para tokoh dari masa kemasa yang sangat berjasa dalam merumuskan konsep maqashid syariah sebagai sebuah disiplin ilmu yang mandiri (Safriadi 2014).

a. Maqashid syariah sebagai doktrin dan metode.

Doktrin maqashid syariah adalah melahirkan sebuah capaian hukum yang menjamin dan melestarikan kemaslahatan bagi seluruh umat manusia. Ada 5 hal yang harus selalu terlindungi dan terjamin dalam perjalanan hidup manusia, agama, jiwa, akal, harta dan keturunan. Untuk mencapai perlindungan dan penjaminan tersebut, dibuatlah tiga skala prioritas yang berbeda namun saling melengkapi, yaitu pertama dharuriyyat (tujuan primer) yang didefinisikan sebagai sebuah tujuan yang harus ada, bila tidak adanya hal tersebut akan tidak tercapai atau rusak 
salah satu dari lima unsur tersebut, kedua al-hajiyyat (tujuan sekunder) yang didefinisikan sesuatu yang dengan adanya dapat mempermudah terlaksana tujuan dharuriyyat dan ketiga al-tahsinat (tujuan tersier) yang didefinisikan sebagai sesuatu yang bukan sebuah kebutuhan yang mendasar, tetapi kehadiranya hanya bersifat memperindah proses terwujudnya al-hajiyyat dan dharuriyyat (Wahyudi 2007). Doktrin seperti ini perlu diperhatikan dalam setiap aplikasi hukum yang menyangkut dengan masyarakat umum seperti itsbat hilal dalam penetapan awal bulan Ramadhan di Indonesia.

Sebagai metode dalam menjawab hukum atau melahirkan hukum Islam, maqashid syariah bisa dijadikan sebuah alternatif dalam mendialogkan teks hukum dengan konteksnya. Maqashid syariah mampu berjalan harmonis dalam memberikan kepastian hukum dalam keadaan fakta sosial yang terus berkembang dan berubah. Ada tiga elemen yang harus diperhatikan dalam melahirkan hukum dengan metode maqashid syariah, yaitu teks (ushul), realitas (istiqra'/tahlil) dan tujuan hukum (maqashid). Dalam merealisasikan metode maqashid syariah perlu dilihat realitas yang menjadi dasar ketimpangan dalam masyarakat seperti sosial ekonomi, gender, etnisitas dan hal-hal yang menimbulkan kedhaliman lainnya. Dengan melihat pada realita, maka makna teks akan sangat cocok dalam melahirkan sebuah tujuan dalam setiap hukum yang akan dilahirkan (Marcoes and Ali 2018).

b. Konsep maqashid syariah.

Maqashid syariah sangat relevan dengan kondisi sosial keagamaan di Indonesia, dimana masyarakat yang manyoritasnya umat Islam dengan latar belakang pemahaman agama yang berbeda-beda, kondisi geografis yang luas dan berpulau-pulau membuat praktik beragama yang berbeda-beda, sebagai contoh metode penentuan awal bulan Ramadhan di Indonesia yang sampai tahun ini masih berbeda-beda. Perbedaan ini akan bisa disatukan bila sama-sama mengacu kepada konsep maqashid syariah dalam penetapan hukum. Menurut Yudian Wahyudi, kondisi ini yang mendorong para pemikir Islam seperti Hasbi Ash Shiddieqy dan tokoh-tokoh reformis setelahnya berupanya untuk mewujutkan hukum Islam yang berazas keindonesiaan atau sering disebut dengan fikih Indonesia atau fikih konstitusional (Wahyudi 2007).

Prinsip dasar syariat Islam adalah kemaslahatan bagi umat manusia dalam menunaikan hak-hak sebagai manusia, karena Allah tidak ada sedikitpun 
kepentingan dalam pemberlakuan syariat. Oleh karenanya, pertimbangan kemanusiaan dalam perumusan hukum sangat dianjurkan. Menurut Ibnu 'Asyur, ada tiga cara untuk mengetahui maqashid syariah, pertama dengan cara observasi induktif, yakni mengkaji syariat dari segala aspek, baik mengkaji hukum yang telah diketahui 'illat nya, maupun mengkaji hukum yang sama 'illat nya. Hal ini bertujuan untuk mengetahui maqshad dari pensyariatan hukum tersebut untuk kemudian disimpulkan bentuk maslahat yang terkandung dalam setiap 'illat hukum. Kedua mencari nilai universal dari tektual ayat Alquran, seperti kemudahan, kebencian terhadap kerusakan, menguasai hak orang lain secara ilegal, menjauhi permusuhan dan mengedepankan kelapangan. Ketiga menemukan maqashid syariah dari hadis yang mutawatir, baik mutawatir ma'nawi yakni nilai maqashid yang diperoleh dari sekelompok sahabat yang melihat perbuatan Nabi Saw, maupun mutawatir 'amali yakni nilai maqshid yang didapati dari seorang sahabat yang sering bersama Rasulullah (Safriadi 2014).

Bila dilihat dari keterlibatan dengan urusan umat, maka maslahah dibagi menjadi tiga, pertama dharuriyyat, yaitu kemaslahatan yang harus ada dan apabila tidak ada, akan merusak sistem atau tatanan kehidupat umat. Kedua hajiyat yaitu suatu kemaslahatan yang harus ada dalam memelihara tatanan umat, hanya saja bila tidak terpenuhi tidak berakibat kerusakan pada tatanan kehidupan umat. Ketiga tahsiniyyat yaitu suatu kemaslahan yang dapat memperlengkap dalam merealisasikan kebagusan tatanan kehidupan umat. Bila dilihat dari sisi keumuman umat, maka maslahah dibagi dua macam, pertama maslahah kulliyah yaitu kemaslahatan yang dapat dirasakan oleh semua manusia atau sebahagian manusia. Yang kedua maslahah juziyyah yaitu kemaslahatan yang hanya dirasakan oleh sebahagian kelompok atau seorang individu saja. Bila dilihat dari segi kebutuhan manusia untuk meraihnya, maka kemaslahatan dibagi kepada tiga. Pertama qat'iyyah yaitu kemaslahatan yang sudah jelas ditunjuki oleh nas. Kedua dhanniyah yaitu kemaslahatan yang kemaslahatan yang didapati melalui penilaian akal. Ketiga wahmiyyah yaitu kemaslahatan yang sekilas terlihat secara akal bermanfaat, namun setelah ditinjau mendalah terdapat makna sebaliknya (Safriadi 2014).

c. Sadd al-dhari'ah dalam maqashid syariah.

Sadd al-dhari'ah adalah salah satu sarana untuk memastikan dan menjaga maqashid syariah dan termasuk salah satu aplikasi praktis dari aplikasi-aplikasi praktik yang terikat dengan kemaslahatan. Sadd al-dhari'ah dan maqashid syariah 
merupakan sebuah konseb yang lahir dari nas yang digeneralisasi pada nas perintah dan larangan yang partikular, hanya saja Sadd al-dhari'ah lebih khusus (perbuatan mubah yang mengandung manfaat atau mudharat) ketimbang maqashid syariah yang mencakupi persoalan umum dan khusus. Berbicara masalah Sadd al-dhari'ah adalah berbicara masalah nilai kemaslahatan atau nilai keruasakan yang ditimbulkan dari sebuah perbuatan. Efek dari sebuah kerusakan adakalanya pasti, adakalanya kebanyakan terjadi, baik secara umum ataupun secara khusus (Jafar 2017).

\section{Sidang Itsbat Hilal}

Di Indonesia, sidang itsbat dalam penetapan awal bulan Ramadhan, Syawal dan Zulhijjah mulai dikenal setelah terbentuk Departemen Agama pada tahun 1946, dimana salah satu tugas yang diembankan kepada Departemen Agama saat itu adalah menetapkan hari libur keagamaan yang termasuk di dalamnya penetapan 1 Ramadhan, 1 Syawal sebagai hari Raya Idul Fitri dan 10 Zulhijjah sebagai hari raya Idul Adha. Mengingat persoalan hisab dan rukyat selalu menjadi penyebab perbedaan dalam penetapan awal bulan hijriah, maka pada tahun 1972 dibentuklah Badan Hisab Rukyat Departemen Agama yang diketuai oleh Sa'adoeddin Djambek. Kehadiran Badan Hisab Rukyat ini diharapkan mampu menyatukan dua mazhab (Hisab dan Rukyat) dalam mengawali Ramadhan, Syawal dan Zulhijjah agar terjaga persatuan dan ukhwah islamiah umat Islam Indonesia dalam beribadah dalam konseb moderasi agama. Melihat realitas sekarang, peristiwa perbedaan dalam penetapan awal bulan Ramadhan, Syawal dan Zulhijjah masih sama seperti sebulum tahun 1946, bahkan perbedaan dan potensi keretakan keharmonisan umat sangat terasa akibat majunya teknologi media komunikasi saat ini. Sampai saat ini, jangankan hisab hakiki, hisab 'urfi saja masih banyak kelompok yang menggunakan atau mengamalkan (Ismail 2018).

Dalam konsep fikih dan ilmu falak, tidak semua kesaksian hilal bisa langsung diterima untuk dijadikan istbat rukyah hilal. Adil dan syahadah belum cukup tanpa diverifikasi keilmiahan nya, praktik verifikasi kesaksian hilal telah dilakukan oleh sabat Nabi saat sebelum rukyah hilal di itsbatkan, sebagaimana diceritakan dalam kitab al-Ilmu al-Mansyur fi Isbati al-Syuhur berikut ini (Al-Subky 1329).

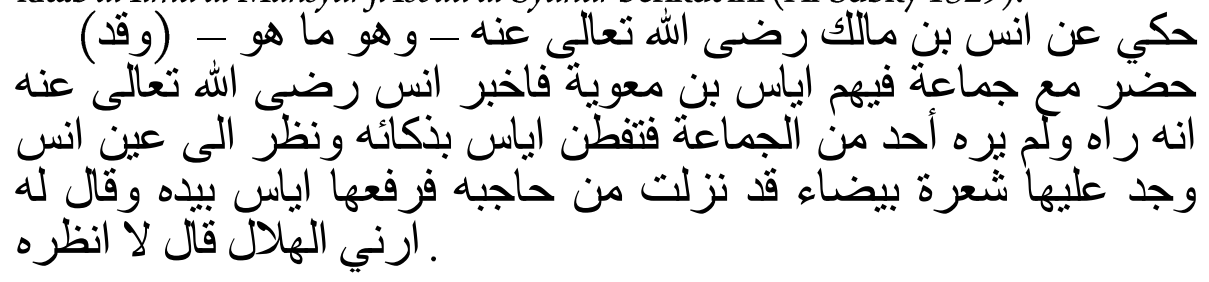


Dihikayahkan dari Anas bin Malik RA. Menghadiri rukyah hilal beserta jamaah termasuk di dalamnya Iyas bin Muawiyah. Anas mengabarkan bahwa ia nampak melihat hilal, padahal tidak ada seorang jamaah pun melihatnya. Lalu Iyas dengan kecerdikannya melihat kepada mata Anas, lalu didapatinya sehelai rambut putih yg turun di alisnya sehingga menutup pelupuk matanya. kemudian Iyas mengangkat rambut tersebut, lalu iyas bertanya kepada Anas, apakah masih nampak hilal? Lalu anas menjawab tidak lagi saya melihatnya.

a. Landasan hukum sidang itsbat di Indonesia.

Kebijakan pemerintah Republik Indonesia dalam menetapkan awal bulan hijriyah di Indonesia mengacu kepada prinsib dasar musyawarah, dimana semua elemen yang ada kaitannya dengan hisab rukyat diikutsertakan dalam musyawarah penetapan awal bulan hijriah atau sidang itsbat. Selain Kemeterian Agama yang merupakan penaggung jawab dalam persoalan penetapan awal bulan hijriah, juga dilibatkan Peradilan Agama, Majelis Ulama Indonesia, ormas Islam, perguruan tinggi, Badan Meteorologi Klimatologi dan Geofisika, Pemerintah Daerah dan tokoh falak. Dalam kebijakan pemerintah sudah jelas tertulis bahwa selain bulan Ramadhan, Syawal dan Zulhijjah, pemerintah dalam menetapkan awal bulan hijriah menggunakan data hisab, yaitu bulan baru dianggap ada bila tinggi hilal di Indonesia di atas 2 derajat saat terbenam matahari pada hari 29 bulan yang sedang berjalan atau umur hilal sudah lebih 8 jam dihitung dari saat konjungsi. Untuk awal bulan Ramadhan, Syawal dan Zulhijjah, pemerintah menetapkan melalui sidang itsbat, data hisab dan hasil rukyah hilal hanya sebagai masukan saja (Kementerian Agama 2019). Dari kebijakan ini, diharapkan pemerintah menjadi otoritas tunggal dalam persoalan penetapan awal bulan hijriah di Indonesia, walau kenyataannya sampai hari ini belum mampu terwujud, dimana hampir setiap tahun ada berita di media tentang mengawali puasa yang berbeda dengan hasil ketetapan pemerintah.

Untuk mendukung kebijakan pemerintah, Majelis Ulama Indonesia telah melahirkan fatwa nomor 2 Tahun 2004 tentang penetapan awal bulan Ramadhan, Syawal dan Zulhijjah. Dalam fatwa MUI melahirkan 4 ketetapan dan 1 rekomendasi. Ketetapan pertama, penetapan awal Ramadhan, Syawal dan Zuhijjah dilakukan berdasarkan metode rukyah dan hisab oleh pemerintah RI cq Menteri Agama dan berlaku secara nasional. Kedua seluruh umat Islam di Indonesia wajib menaati ketetapan pemerintah RI tentang penetapan awal Ramadhan, Syawal dan Zulhijjah. Ketiga dalam menetapkan awal Ramadhan, Syawal dan Zulhijjah, 
Menteri Agama wajib berkonsultasi dengan Majelis Ulama Indonesia, ormasormas Islam dan instansi terkait. Keempat hasil rukyat dari daerah yang memungkinkan hilal dirukyat walaupun di luar wilayah Indonesia yang matlak nya sama dengan Indonesia dapat dijadikan pedoman oleh Menteri Agama RI. Sedangkan rekomendasinya adalah agar MUI mengusahakan adanya kriteria penetapan awal Ramadhan, Syawal dan Zulhijjah untuk dijadikan pedoman oleh Menteri Agama dengan pembahasannya bersama ormas-ormas Islam dan para ahli terkait (MUI 2004).

Bila dilihat pada isi fatwa MUI dan kebijakan pemerintah terhadap penetapan awal bulan hijriah, maka sidang itsbat yang selama ini dilakukan oleh Kementerian Agama RI hanya sebagai wadah untuk bermusyawarah dalam menetapkan awal Ramadhan, Syawal dan Zulhijjah. Bukan verifikasi hasil rukyah hilal yang dilaporkan di lapangan, bahkan dalam kebijakan pemerintah secara tegas mengatakan bahwa laporan rukyah hilal dan hasil hisab hanya sebagai masukan saja, dalam artian keputusan sidang itsbat murni hasil musyawarah dalam mencari kemaslahatan. Oleh sebab itu wajar Susiknan Azhari dalam Ensiklopedi hisab rukyat mendefinisikan sidang itsbat sebagai sidang untuk menetapkan kapan jatuhnya 1 Ramadhan, Syawal dan Zulhijjah yang dihadiri oleh berbagai ormas di Indonesia dan langsung dipimpin oleh Menteri Agama RI (Azhari 2008). Tidak adanya verifikasi hilal dalam sidang itsbat wajar terjadi di Indonesia, mengingat sampai saat ini belum ada kriteria tunggal yang dapat dipedomani oleh pemerintah sebagaimana tercantum dalam rekomendasi fatwa MUI no 2 tahun 2004.

Dalam konseb ushul fikih, sidang itsbat hilal merupakan sebuah kewajiban bagi negara sebagai representasi imam dalam hal kewajiban berpuasa bagi masyarakat umum, artinya bila tidak ada itsbat hilal Ramadhan, maka yang wajib berpuasa hanya yang melakukan rukyah hilal saja, untuk yang tidak ikut melakukan rukyat boleh memilih kemana yang diyakininya, dengan adanya itsbat hilal oleh pemerintah, tidak ada alasan untuk mengatakan belum wajib puasa bila berada dalam wilayah hukum Indonesia.

b. Konseb matlak dalam sidang itsbat

Dalam penetapan awal bulan hijriah, khususnya awal bulan Ramadhan, Syawal dan Zulhijjah, konseb matlak menjadi penting, mengingat banyak masyarakat Indonesia yang terpengaruh dengan pengumuman atau penetapan awal bulan hijriah seperti di Saudi Arabia, bahkan di Aceh sering terjadi perbedaan dalam 
mengawali puasa Ramadhan karena sebahagian ulama menganggap matlak Aceh hanya daratan pulau Sumatera saja. Kasus yang paling dekat, di Aceh ada sebahagian masyarakat yang mengawali puasa Ramadhan $1440 \mathrm{H}$ pada hari Selasa 7 Mei 2019, padahal hasil sidang itsbat memutuskan 1 Ramadhan $1440 \mathrm{H}$ di Indonesia jatuh pada hari Senin 6 Mei 2019. Begitu juga dengan 1 Syawal $1440 \mathrm{H}$ ada sebahagian masyarakat Indonesia yang berlebaran Selasa 4 Juni 2019 dengan alasan ikut keputusan Arab Saudi, padahal sidang itsbat memutuskan 1 Syawal $1440 \mathrm{H}$ untuk Indonesia jatuh pada hari Rabu 5 Juni 2019.

Mengacu kepada isi kebijakan pemerintah dalam menetapkan awal bulan hijriah di Indonesia dan fatwa MUI No. 2 Tahun 2004 tentang penetapan awal Ramadhan, Syawal dan Zulhijjah, matlak hilal dalam sidang itsbat adalah seluruh wilayah negara Republik Indonesia, artinya hasil sidang itsbat berlaku untuk seluruh masyarakat muslim yang berdomisili di Negara Kesatuan Republik Indonesia. Kebijakan pemerintah dan fatwa MUI berkehendaki tidak ada dua hari untuk 1 Syawal dan 1 Ramadhan di Indonesia, namun penyatuan ini masih sebatas wacana, mengingat sidang itsbat itu masih jauh dari pemahaman fikih. Sidang itsbat dalam fikih, untuk memverifikasi kebenaran rukyah hilal dan pemberlakuan rukyah hilal yang diterima untuk wilayatul hukmi. Di Indonesia, verifikasi kesaksian hilal tidak bisa dilakukan karena belum ada kriteria tunggal, masing-masing ormas masih berpegang pada kriteria masing-masing, sehingga makna sidang itsbat hilal di Indonesia hanya sebatas musyawarah untuk menentukan kapan cocoknya dimulai 1 Ramadhan, Syawal dan Zulhijjah.

c. Konseb rukyah hilal dalam sidang itsbat

Di Indonesia, tugas untuk mengamati hilal pada penentuan awal Ramadhan, Syawal dan Zulhijjah dimotori oleh tim Hisab Rukyat Kementerian Agama di setiap Kabupaten/Kota di seluruh Indonesia. Dalam hal keikutsertaan dalam rukyat tentunya ada ormas Islam dan instansi terkait yang selalu dilibatkan. Namun untuk kesaksian hilal sebagai pertimbagan sidang itsbat harus yang telah disumpah oleh hakim Peradilan Agama. Pengadilan agama sama dengan Mahkamah Syar'iyyah di Aceh (Yahya 2013). Keterlibatan hakim dalam rukyah hilal atas dasar Undang-undang Nomor 3 Tahun 2006 atas perubahan Undang-undang Nomor 7 Tahun 1989 tentang Peradilan Agama. Dalam hal ini hakim Peradilan Agama diberi wewenang untuk menetapkan itsbat atas kesaksian dilihat atau tidak dilihatnya hilal saja, bukan mengitsbat untuk penetapan tanggal baru bulan hijriah 
atas kesaksian terlihat hilal. Selain itu, hakim juga memverfikasi kesaksian dengan data hisab, serta kesehatan mental sipelaku rukyah hilal. Dari hasil itsbat hakim di lokasi rukyah hilal, kemudian dilaporkan ke Jakarta sebagai pertimbangan dalam sidang itsbat penetapan awal bulan hijriah (Santoso 2012). Rukyah yang diterima dalam sidang itsbat penetapan awal bulan hijriah adalah bulan yang dilihat dengan mata telanjang atau dibantu dengan teleskop, bukan rukyah dengan olah citra hilal (Marpaung 2015).

Dalam fatwa MUI Nomor 2 Tahun 2004 tersebutkan pada poin 4 bahwa rukyah hilal yang dijadikan pertimbangan sidang itsbat penetapan awal Ramadhan, Syawal dan Zulhijjah tidak hanya hasil rukyah di wilayah hukum Indonesia, juga bisa diterima hasil rukyah hilal di negara lain yang satu matlak dengan Indonesia. Namun dalam fatwa tersebut tidak menyebutkan luas matlak atau konseb matlak yang bisa dikatakan satu matlak, yang jelas tersebutkan hanya matlak pemberlakuan hasil sidang itsbat, yaitu seluruh wilayah Negara Kesatuan Republik Indonesia. Mengingat belum jelasnya konseb matlak rukyah hilal, boleh diusulkan konseb matlak yang dimaksud dalam fatwa MUI tersebut adalah konseb matlak imkan rukyah. Seluruh wilayah di permukaan bumi bila masuk dalam peta hilal sudah imkan rukyah bisa di anggab satu matlak. Sebagai contoh peta imkan rukyah bisa dilihat gambar di bawah ini.

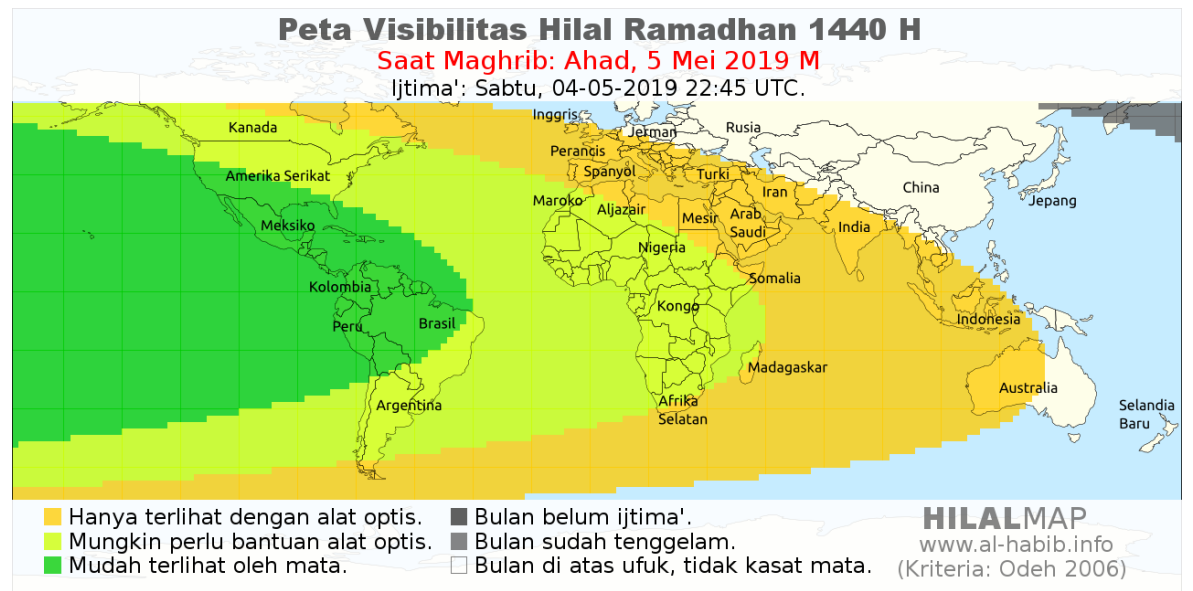

\section{Gambar 1. Peta Visibilitas Hilal Ramadhan 1440 H \\ Sumber: Hilal Map, www.al-habib.info}


Berdasarkan gambar 1. bisa dengan mudah mengetahui negara mana saja yang hilal sudak mungkin dilihat atau imkan rukyah dan negara mana saja yang belum imkan rukyah, dengan berpedoman pada imformasi peta hilal tentunya sangat membantu semua negara untuk saling berbagi informasi hasil rukyah di negara masing-masing untuk rujukan negara lain yang berada dalam satu matlak hilal.

\section{Kesimpulan}

Melihat realita di Indonesia, perbedaan dalam mengawali puasa Ramadhan sangat sulit untuk disatukan, mengingat perbedaan ini sudah masuk dalam katagori politik identitas ormas-ormas Islam di Indonesia. Di satu sisi perbedaan ini sangat positif, dimana dengan adanya perbedaan, materi terhadap sesuatu yang diperselisihkan dominan untuk dipelajari dan terus dikembangkan, namun disisi lain perbedaan ini mampu memecah belah umat Islam dan retak ukhwah islamiyah yang merugikan umat Islam itu sendiri. Menurut Ahmad Wahidi ada 3 faktor yang menyebabkan selalu terjadinya perbedaan dalam mengawal Ramadhan, Syawal dan Zulhijjah, pertama berbeda dalam memahami nas tentang mengawali dan mengakhiri puasa yang berahir pada dikotomi antara metode hisab dan rukyat. Kedua ada perbedaan sistem perhitungan (hisab), ada hisab hakiki dan ada hisab 'urfi, yang kedua ini masih ada yang mengamalkan di Indonesia. Ketiga adanya perbedaan dalam memilih kriteria masuk awal bulan hijriah, sistem hisab boleh sama, bila kriteria yang dipakai berbeda akan menghasilkan penetapan yang berbeda.

Deretan masalah dalam mengawali puasa Ramadhan di Indonesia seolah-olah tidak akan ada titik temu untuk sepanjang masa, namun perlu digaris bawahi bahwa penetapan awal Ramadhan, Syawal dan Zulhijjah bukan hanya persoalah ibadah yang menyangkut persoalan individu, jauh dari itu, ia termasuk masalah sosial yang ikut dalam ibadah penting umat Islam, dimana di dalamnya ada puasa dan haji sebagai ibadah individu yang wajib, perlu dilihat juga berhari raya Idul Fitri dan Idul Adha yang merupakan ibadah sosial umat Islam Indonesia yang perlu penyeragaman untuk ketertiban umum seperti cuti kerja, pawai takbiran dan agenda keberangkatan jamaah haji. Keteraturan sosial harus diperhatikan, mengingat ciri-ciri orang bertakwa adalah shaleh secara individu dan shaleh secara sosial. 
Sidang itsbat penetuan awal bulan Ramadhan di Indonesia merupakan persoalan ibadah yang sarat dengan dimensi sosial, maka maqashid syariah sangat perlu untuk dipertimbangkan dalam peristiwa sidang itsbat. Hasil sidang itsbat harus menjadi otoritas tunggal di Indonesia, mengingat bagi pengikut mazhab Syafi'i yang merupakan manyoritas di Indonesia, itsbat hilal menjadi sebab syar'i wajibnya puasa bagi orang yang tidak melihat hilal, bukan karena adanya maklumat atau ihkbar tentang awal bulan Ramadhan. Apalagi kewajiban untuk mengikuti hasil sidang itsbat telah difatwakan oleh Majelis Ulama Indonesia, oleh karenanya tidak ada alasan untuk menentang atau tidak mengikuti hasil sidang itsbat dalam penentuan awal Ramadhan, Syawal dan Zulhijjah bagai masyarakat muslim di Indonesia.

Praktik sidang itsbat penentuan awal bulan Ramadhan sudah sangat bagus di Indonesia, dimana hilal yang diterima sebagai pertimbangan sidang itsbat adalah hilal yang sudah disumpah sipengamat oleh hakim Peradilan Agama dan kesaksian hilal bukan menjadi satu-satunya alasan penetapan dalam putusan sidang itsbat awal bulan Ramadhan, namun itu salah satunya pertimbangan, ada pertimbangan lain, yaitu hasil perhitungan ilmu falak dan hasil masukan dan saran dari tokoh agama, ormas dan para ahli yang hadir dalam acara sidang itsbat di Jakarta. Bila ada kesaksian hilal yang telah disumpahkan, sesuai dengan data hisab ilmu falak (hilal sudah imkan rukyah) dan sepakat para hadirin peserta sidang itsbat, baru kesimpulan diambil untuk diputuskan dan ditetapkan. Praktik ini sudah sangat sempurna, walau masih banyak yang perlu dibenahi, dimana tidak semua lokasi pengamatan di Indonesia di bekali oleh tim yang ahli dan instrumen yang memadai yang kadang kala ikut mewarnai kesaksian hilal.

Dalam maqashid syariah, sidang itsbat penetuan awal bulan Ramadhan di Indonesia, secara khusus termasuk dalam katagori dharuriyyat, dimana para pengikut fikih mazhab imam Syafi'i itsbat hilal menjadi penyebab syar'i wajib puasa Ramadhan, bila belum ada itsbat hilal dari pemerintah belum ada kewajiban untuk berpuasa bagi yang tidak secara langsung melihat hilal. Secara umum sidang itsbat penetuan awal Ramadhan di Indonesia termasuk dalam katagori hajiyat, dimana sidang itsbat diperlukan untuk penyatuan dan ketertiban dalam melaksanakan ibadah umat yang ada kaitannya dengan persoalan sosial. Bisa dibayangkan bagaimana kacaunya memulai ibadah puasa Ramadhan bila tidak ada sidang itsbat, bisa jadi untuk 1 Ramadhan diawali dengan hari yang berbeda samapai 5 hari, 
buktinya dengan ada sidang itsbat saja, masyarakat Indonesia dalam mengawali puasa Ramadhan sampai 3 hari, misalnya pemerintah memulai puasa tanggal 6 , ada yang sudah memulai tanggal 5 dan ada yang akan memulai di tanggal 7.

Nilai-nilai maqashid syariah telah terimplentasikan dalam sidang itsbat penentuan awal Ramadhan, dimana inti dari sidang itsbat di Indonesia adalah musyawarah dan mencari mana jalan terbaik untuk umat dalam menjalankan ibadah puasa dengan pertimbagan hisab dan rukyah hilal, dengan menjunjung tinggi nilai persatuan agar terhindar perpecahan dan agar kokohnya persatuan dan kesatuan umat Islam Indonesia. Menolak sidang itsbat sama halnya menolak kemaslahatan, menolak kemaslahatan sama halnya mengundang kemudharatan, mengundang kemudharatan adalah perbuatan yang keji dan terlarang. Saran dari penulis, kedepan pemerintah harus berbenah dari kekurangan dalam acara penentuan awal bulan hijriah, selain kuantitas titik rukyah hilal yang memada, kualitas perukyah disetiap titik rukyah hilal harus dipertimbangkan, seperti tenaga ahli dan instrumen yang memadai di setiap titik rukyah resmi Kementerian Agama di seluruh Indonesia.

\section{DAFTAR PUSTAKA}

Al-Subky, Taqiyuddin Ali bin Abdul Kafy. 1329. Al-Ilmu Al-Mansyur Fi Isbati AlSyuhur. Mesir: Kurdistan al-Ilmiah.

Azhari, Susiknan. 2008. Ensiklopedi Hisab Rukyat. 2nd ed. Yogyakarta: Pustaka Pelajar.

Ismail. 2018. "Sistem Kalender Pada Masa Kerajaan Samudera Pasai." Jurnal Syarah 7(1).

Jafar, M. 2017. "Kriteria Sadd Al-Dhari'ah Dalam Epistemologi Hukum Islam." Pascasarjana UIN Ar-Raniry Banda Aceh.

Kementerian Agama. 2019. Ephemeris Hisab Rukyat. Jakarta: Kementerian Agama Republik Indonesia.

Marcoes, Lies, and Mukti Ali. 2018. Maqashid Al-Islam: Konsep Perlindungan Manusia Dalam Perspektif Islam. Jakarta: Yayasan Rumah Kita Bersama.

Marpaung, Watni. 2015. Pengantar Ilmu Falak. Jakarta: Prenadamedia Grup.

MUI. 2004.Penetapan Awal Ramadhan, Syawal Dan Zulhijjah. Indonesia.

Qulub, Siti Tatmainul. 2015. "Telaah Kritis Putusan Sidang Itsbat Penetapan Awal Bulan Qamariyah Di Indonesia Dalam Perspektif Ushul Fikih.” Al- 
Ahkam 25.

Rohmah, N. 2018. "Dialog Teori Konflik Dialektika-Fungsional." In Proceedings of Annual Conference for Muslim Scholars (April): 993-1001.

Safriadi. 2014. Diskursus Maqashid Al-Syariah Ibnu 'Asyur. Aceh Utara: Sefa Bumi Persada.

Santoso, Eko Heri. 2012. "Sidang Itsbat Rukyatul Hilal Berdasarkan UndangUndang Nomor 3 Tahun 2006 Tentang Perubahan Undang-Undang Nomor 7 Tahun 1989 Tentang Peradilan Agama." Universitas Jember.

Wahidi, Ahmad. 2011. "Menyatukan Penetapan 1 Ramadhan, Syawal Dan Zulhijjah Di Indonesia." Jurisdictie 2(2).

Wahyudi, Yudian. 2007. Ushul Fikih versus Hermeneutika (Membaca Islam Dari Kanada Dan Amerika). Yogyakarta: Pesantren Nawesea Press.

Yahya, Nasrullah. 2013. Sosiologi Hukum Islam. 2nd ed. Lhokseumawe: Sefa Bumi Persada. 